\title{
Peptic Ulcer Diseases in Patients with Liver Cirrhosis and Portal Hypertension: Experience in a Tertiary Level Hospital in Bangladesh
}

\author{
Moben $\mathrm{AL}^{1}$, Kafee $\mathrm{MA}^{2}$, Kabir $\mathrm{MJ}^{3}$, Raha $\mathrm{A}^{4}$, Majid $\mathrm{F}^{5}$, Razzak $\mathrm{MA}^{6}$ \\ DOI:https://doi.org/10.3329/jafmc.v16i2.55303
}

\begin{abstract}
Introduction: Cirrhosis of liver and peptic ulcer disease (PUD) are very common in Bangladesh. PUD may coexist with cirrhosis and portal hypertension. Haematemesis and melaena in cirrhosis of liver are not always from ruptured oesophageal varices; rather it may be due to bleeding peptic ulcer disease.
\end{abstract}

Objective: To find the prevalence of PUD among patients with liver cirrhosis and portal hypertension.

Materials and Methods: This cross sectional, descriptive study was conducted on 96 patients of cirrhosis of liver diagnosed with oesophageal varices at endoscopy unit of Kurmitola general hospital, during endoscopic evaluations in 4 months period from september 2017 to december 2017.

Results: Total cirrhotic patients enrolled were 96 (M=61, $\mathrm{F}=35)$, mean age was $51.8 \pm 14.2$ yrs (18-86years). Hepatitis B virus (HBV) was the leading cause of cirrhosis in $54.1 \%$, Hepatitis $\mathrm{C}$ virus (HCV) $5.2 \%$, proven non-alcoholic steatohepatitis (NASH) were $11.5 \%$ and rest were from unknown aetiology. Their average ChildTurcotte-Pugh (CTP) score were 8.6 (12-5), 37.6\% associated with portal hypertensive gastropathy. Grade-III oesophageal varices found in 52 patients, whereas grade-II in 25 patients. Among this 96 patients $39(40.6 \%)$ revealed peptic ulcer disease more in the form of gastric ulcer $(n=23)$ than duodenal ulcer $(n=10)$ and both $(n=6)$. Most of the ulcers belonged to Forrest class III (76.9\%).

Conclusions: Variceal bleeding and portal hypertensive gastropathy are the common causes of bleeding and anaemia in patients with cirrhosis of liver. Peptic ulcer disease has been found to be one of the potential cause of haematemesis, melaena, and anaemia among these patients in Bangladesh. Large multicenter controlled studies are needed to confirm the reports.

Key-words: Cirrhosis of liver, Portal hypertension, Oesophageal varices, Peptic ulcer disease, Haematemesis, Melaena.

\section{Introduction}

Bangladesh is a developing country and considered as tropical country. Liver disease is a very common problem with which patient seeks medical advice. It is the third common cause of hospital admission. In a multicenter study conducted on 59,227 patients at medical college level (tertiary) hospitals reveals $13.2 \%$ presented with some sorts of liver problems, 37\% of them have been suffering from cirrhosis of liver and its complications ${ }^{1}$. Liver disease is the third commonest cause of hospital death in medicine departments of medical college hospitals in Bangladesh². Peptic ulcer disease is also common gastroenterological disease here. Peptic ulcers have frequently observed in patients with cirrhosis of liver during upper GI endoscopy. Abnormal acid, pepsin, gastrin secretion and contribution by the altered cytoprotection are the underlying factor for increased frequency of peptic ulcer disease in patient with cirrhosis of liver².

Haematemesis and Melaena is one of the common and life threatening complications among the cirrhosis of liver patients who had portal hypertension. During the first diagnosis of cirrhosis about $60 \%$ of the patients with ascites have any grade of oesophageal varices and it is $40 \%$ when presented without ascites $^{3}$. Once the varices have developed in cirrhosis of liver patients they have the tendency to increase in size even rupture at any grade of varices ${ }^{4}$. Variceal haemorrhage carries a significant risk of mortality of $7-15 \% \%^{5-7}$. However, haematemesis not always arises from ruptured oesophageal varices, $48 \%$ bled from variceal rupture (oesophageal and gastric), $34 \%$ from peptic ulcer, $18 \%$ had insufficient evidence of source ${ }^{8}$. Management of bleeding peptic ulcer disease and ruptured oesophageal varices differs from each other. Outcome even after standard care are also variable. So, the aim of the study is to evaluate the presence of peptic ulcer disease in patients with cirrhosis of liver with portal hypertension in a tertiary level hospital in Bangladesh.

\section{Materials and Methods}

This cross sectional, descriptive study was conducted at Kurmitola General Hospital, Dhaka, Bangladesh in the period from September 2017 to December 2017 and was approved by institutional ethical committee. Patients who had the diagnosis of liver cirrhosis attended to our endoscopy department for upper GI endoscopy and found oesophageal varices or gastric varices, were included in the study.

1. Dr Ahmed Lutful Moben, MBBS, MD, Medical Officer, Kurmitola General Hospital, Dhaka 2. Dr Md Abdullahel Kafee, MBBS, FCPS, MD, Assistant Professor of Medicine, Kurmitola General Hospital, Dhaka 3. Dr Md Jahangir Kabir, MBBS, MD, Medical Officer, Kurmitola General Hospital, Dhaka 4. Dr Arunanagshu Raha, MBBD, MD, Medical Officer, Kurmitola General Hospital, Dhaka 5. Dr Farjana Majid, MBBS, MPhil, Professor of Microbiology, Tairunnesa Memorial Medical College, Tongi, Gazipur 6. Brig Gen Md Abdur Razzak, MBBS, MCPS, FCPS, APLAR Fellow in Rheumatology, Professor \& Head, Deaprtment of Medicine, Armed Forces Medical College, Dhaka. 
Consecutive 96 patients were enrolled for the study, who gave the written informed consent. Patients who had the history of taking non steroidal anti inflammatory drugs (NSAIDs) or steroids within one month and taking regular Proton pump inhibitor for more than 2 weeks were excluded from the study. Data were collected from the patient's interview, physical examinations and his /her accompanying investigation reports were analysed by SPSS v20.

\section{Results}

In this study, among the 96 patients $61(63.54 \%)$ were male, 35(32.29\%) were female (Fig:1). Mean age were $51.8 \pm 14.2$ years (range: 18-86 years). Table-I describes the age distribution. Among the study patients of cirrhosis of liver HBV took the leading cause (54.2\%) followed by unknown aetiology (29.2\%), Non-alcoholic steatohepatitis (NASH) (11.5\%) and HCV (5.2\%) (Fig:2). To determine the severity of cirrhosis of liver Child-Pugh scoring system had been used 9 . Average Child-Turcotte-Pugh (CTP) score were 8.6 (5-12). There was a tie between Child $B$ and Child $C$ patients ( $n=45$ in each group), higher than Child $A(n=6)$. None of the patient is on any grade of hepatic encephalopathy while enrolled for the study. Grade III oesophageal varices were found in 52 patients and grade II and grade I were 25 and 19 respectively. Thirty six patients out of 96 (37.5\%) had portal hypertensive gastropathy (mild and severe) in association with oesophageal varices. Among this 96 patients 39 (40.6\%) revealed peptic ulcer disease more in the form of gastric ulcer $23(59 \%)$ than duodenal ulcer 10(25.6\%) and both 6 (15.4\%) [Fig: 3]. According to Forrest classification for the activity of ulcer ${ }^{10}$, most of the ulcers are belongs to Class III in 30 patients $(76.9 \%)$ followed by class IIC $(17.9 \%)$ and class IIb (5.1\%). Cirrhosis of liver patient with grade III oesophageal varices caries more ulcer $64.1 \%$ than grade-II and grade-I respectively $25.6 \%, 10.3 \%$ (Table-II). In this study duodenal ulcer is more prevalent in Child A cirrhosis (12.8\% VS 5.1\%). Gastric ulcer is more prevalent in Child B (17.9\% VS 5.1\%) and in Child C (35.9 VS 7.7\%) cases (Table-III). Co-existing peptic ulcer disease and cirrhosis of liver patients presented commonly with peptic dyspepsia (44\%) followed by asymptomatic $38 \%$, upper GI bleeding in $10 \%$ and $8 \%$ upper abdominal pain (Fig: 4).

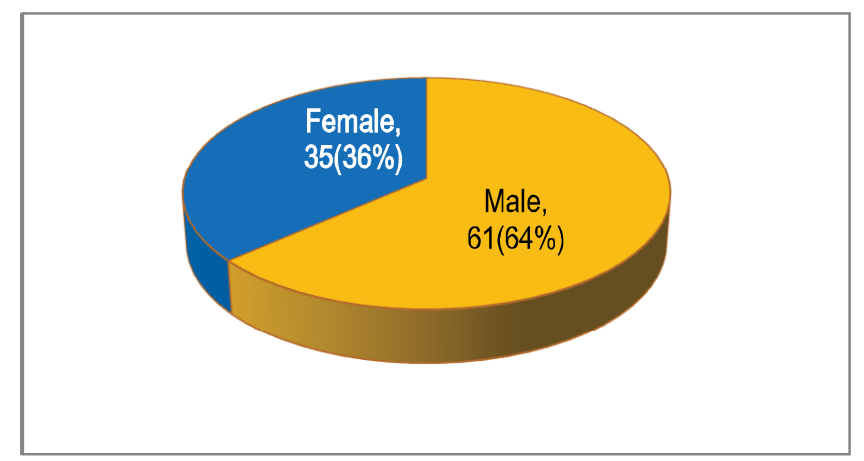

Figure-1: Sex distribution of cirrhotic patients $(\mathrm{n}=96)$

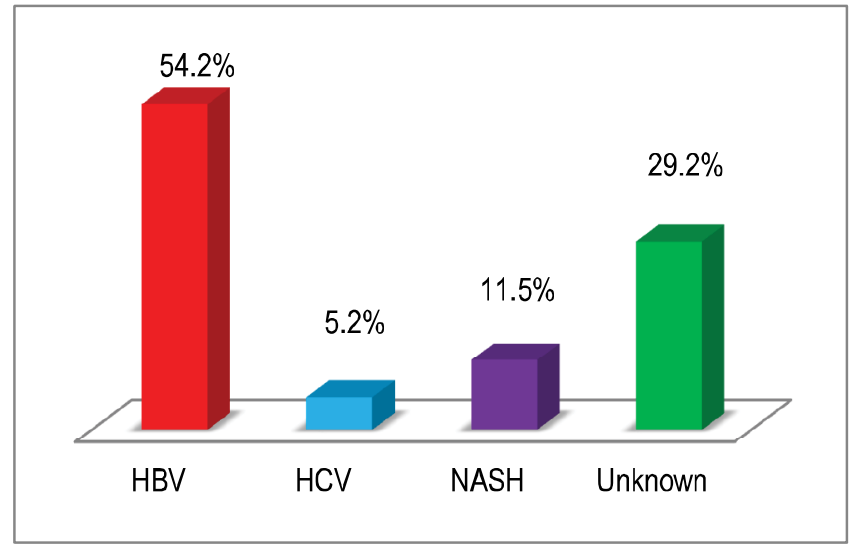

Figure-2: Causes of cirrhosis of liver $(n=96)$.

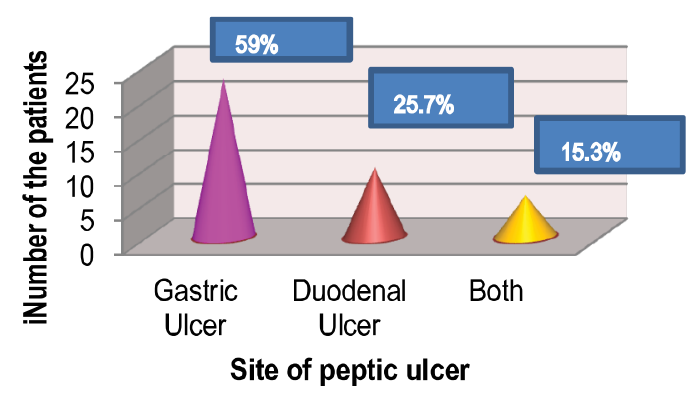

Figure-3: Point prevalence of Gastric ulcer, duodenal ulcer and both in cirrhotic patients $(n=39)$

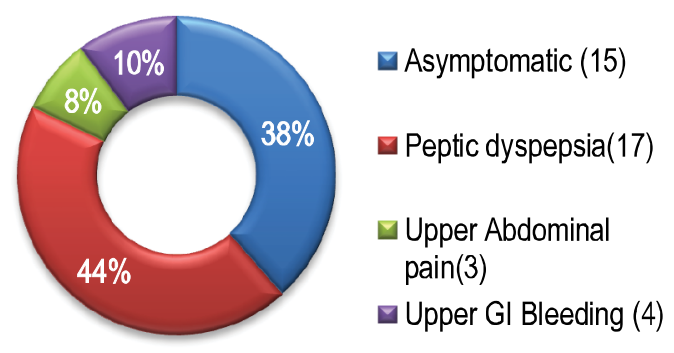

Figure-4: Clinical presentation of Co-existing peptic ulcer disease in cirrhotic patients $(n=39)$.

Table-l: Distribution of cirrhotic patients according to age group $(n=96)$

\begin{tabular}{|c|c|c|}
\hline $\begin{array}{c}\text { Age group } \\
\text { (years) }\end{array}$ & Number of the patients & Percentage \\
\hline $10-19$ & 1 & 1.0 \\
\hline $20-29$ & 5 & 5.2 \\
\hline $30-39$ & 14 & 14.6 \\
\hline $40-49$ & 27 & 28.1 \\
\hline $50-59$ & 16 & 16.7 \\
\hline $60-69$ & 22 & 22.9 \\
\hline $70-79$ & 9 & 9.4 \\
\hline $80-89$ & 2 & 2.0 \\
\hline
\end{tabular}


Table-II: Distribution of Peptic ulcer activity (Forrest class) as per grading of oesophageal varices $(n=39)$

\begin{tabular}{|c|c|c|c|c|}
\hline \multirow{2}{*}{$\begin{array}{l}\text { Oesophageal } \\
\text { varices }\end{array}$} & \multicolumn{3}{|c|}{ Peptic ulcer disease } & \multirow{2}{*}{$\begin{array}{c}\text { Total peptic } \\
\text { ulcer } \\
\text { patients (\%) }\end{array}$} \\
\hline & $\begin{array}{l}\text { Forrest } \\
\text { Class III }\end{array}$ & $\begin{array}{l}\text { Forrest } \\
\text { Class Ilb }\end{array}$ & $\begin{array}{l}\text { Forrest } \\
\text { Class IIc }\end{array}$ & \\
\hline Grade-I & 3 & 1 & 0 & $4(10.3)$ \\
\hline Grade-II & 8 & 1 & 1 & $10(25.6)$ \\
\hline Grade-III & 19 & 5 & 1 & $25(64.1)$ \\
\hline Total & 30 & 7 & 2 & $39(100)$ \\
\hline
\end{tabular}

Table-III: Distribution of peptic ulcer according to severity of cirrhosis of liver $(n=39)$

\begin{tabular}{|l|l|l|l|}
\hline \multirow{2}{*}{ Child Pugh } & \multicolumn{3}{|l|}{ Peptic ulcer } \\
\cline { 2 - 4 } & Gastric Ulcer (\%) & Duodenal Ulcer (\%) & Both (\%) \\
\hline Child A & $2(5.1)$ & $5(12.8)$ & $0(0)$ \\
\hline Child B & $7(18)$ & $2(5.1)$ & $3(7.7)$ \\
\hline Child C & $14(35.9)$ & $3(7.7)$ & $3(7.7)$ \\
\hline Total & $23(59)$ & $10(25.6)$ & $6(15.3)$ \\
\hline
\end{tabular}

\section{Discussion}

In this study among 96 patients male were more than female (64\% vs $36 \%$ ). Mean age was $51.7 \pm 14.2$ (18-86) years. Causes of liver cirrhosis in this study was HBV $54.2 \%$ followed by unknown cause $29.2 \%$, NASH $11.5 \%$, HCV $5.2 \%$. A study conducted at Bangabandhu Sheikh Mujib Medical University in 2014-2016 on 770 patients reveals HBV is the leading cause (49.2\%) followed by NASH $(14.7 \%)$ and HCV $(4.0 \%)^{11}$.

Peptic ulcer disease is very common disease (prevalence of 8-14\%) with which patients present to medical facility ${ }^{12}$. The point prevalence of peptic ulcer disease in Bangladesh; duodenal ulcer $7.4 \%$, gastric ulcer $3.3 \%$ and gastric outlet obstruction as a squeal of peptic ulcer disease $0.4 \%{ }^{13}$. In 1980 peptic ulcer disease in cirrhosis of liver patient was $14.7 \% \%^{14}$. In 1995 in a study of 324 patients with cirrhosis of liver revealed prevalence of peptic ulcer disease at $15.1 \%{ }^{15}$. In 2008 , peptic ulcer disease was more prevalent in cirrhotic patients than those having no cirrhosis $(24.3 \%)^{16}$. It was gradually increasing as found in different literatures. Patients with liver cirrhosis have a higher risk of having peptic ulcer than chronic hepatitis (OR: 4.13, $p=0.03)^{17}$. In a Nationwide population based survey at Taiwan among the 4013 liver cirrhosis, 8013 chronic hepatitis and 7793 normal controls after 7 years follow up has shown that cirrhotic patients are at higher risk of peptic ulcer bleeding (Hazards ratio: 4.2;95\% Cl 3.4-5.3,P $<0.001$ ) 18 $^{18}$. Patients with liver disease had a higher 3 months mortality rates than had no liver disease due to bleeding peptic ulcer. In cirrhotic patients it is higher (25.3\%) compared to chronic hepatitis (20.7\%) and without liver disease $(18.1 \%)^{19}$. These may be contributed by thrombocytopenia due to hypersplenism and decreased thrombopoietin production and also due to deficiency of vitamin-K dependent clotting factors as well as deficiency of $\alpha 1$ anti-trypsin in cirrhotic patients ${ }^{20}$. In this study we found gastric ulcer in 23, duodenal ulcer in 10 and both in 6 cirrhotic patients. Here peptic ulcer prevalence is higher than previous studies in cirrhosis of liver patients ${ }^{17,18}$. Duodenal ulcer is common in compensated cirrhosis than decompensated cirrhosis (16.7\% and $13.3 \%$ respectively) than in normal control (3.3\%); Gastric ulcer is more common in decompensated cirrhosis of liver patient than compensated ( $15 \%$ and $3.3 \%)^{21}$. In this study duodenal ulcer is more prevalent in Child-A and gastric ulcer is more prevalent in Child-B and Child-C. Peptic ulcers are also common in cirrhotic patients with grade-III oesophageal varices than with grade-II and grade-I. Peptic ulcer disease is more prevalent in this study might be due to more decompensated patients were enrolled in present study (average CTP score were 8.6).

Haematemesis from the ruptured oesophageal varices and from the peptic ulcer disease varies in different ways. Sometimes it becomes difficult to determine the cause of bleeding. Though their general management is same but specific management is completely different depending upon underlying cause of haematemesis and melaena. Recovery and mortalities even after standard care is also variable. After first variceal haemorrhage mortality rates are $7.4 \%$ at 48 hours, $24 \%$ in 6 weeks ${ }^{22}$. On the other hand mortality from the bleeding peptic ulcer is $5-10 \%{ }^{23}$. So, if we determine the cause of bleeding in particular case by doing an upper $\mathrm{GI}$ endoscopy as soon as possible and take initiative to manage them, it becomes helpful for the outcome of the patient.

\section{Conclusion}

Point prevalence of peptic ulcer disease is more in cirrhosis of liver patient than in non-cirrhotic. Abnormal acid pepsin secretion and altered cytoprotection is the key role player in cirrhotic patients for increased rate of peptic ulcer, the role of Helicobactor pylori yet to be established. Variceal bleeding and portal hypertensive gastropathy are the common causes of bleeding and anaemia in patients with cirrhosis of liver. This study reveals that, Peptic ulcer disease is one of the potential cause of haematemesis, melaena, and anaemia among these patients in Bangladesh. A large multi-center controlled study is needed for confirmation of the results and to determine the clinical implications.

\section{Acknowledgement}

The authors acknowledge the contribution, co-operation and labor they gave to this study works Dr. Al-Rizwan Russel, Dr. TI Khan, Dr. Md. Nasir Hossain, Dr. Nishat Nawajesh Arpita, Medical officer (Medicine), Mst. Kulsum Akter, Mst. Rokaiya Khatun, Mst. Shabana (Senior staff nurse) and Mrs. Tania Akter (MLSS) of Kurmitola General Hospital, Dhaka.

\section{References}

1. Rahman S, Ahmed MF, Alam MJ et al. Distribution of liver disease in Bangladesh: A cross sectional study. Euroasian J Hepatogastroenterol. 2014; 4(1):25-30.

2. Abedin MF, Hoque MM, Islam ASMS et al. Chronic liver disease is one of the leading causes of death in Bangladesh: 
Experience by death audit from a tertiary Hospital. Euroasian $\mathrm{J}$ Hepatogastroenterol. 2014; 4(1):14-7.

3. Merli M, Nicolini G, Angeloni S et al. Incidence and natural history of small oesophageal varices in cirrhotic patients. Journal of Hepatology. 2003; 38(3):266-72.

4. Franchis RD and Primignani M. Natural history of portal hypertension in patients with cirrhosis. Clinics in Liver Disease. 2001; 5(3):645-63.

5. Abraldes JG, Villanueva C, Banares $\mathrm{R}$ et al. Hepatic venous pressure gradient and prognosis in patients with acute variceal bleeding treated with pharmacologic and endoscopic therapy. Journal of Hepatology. 2008; 48(2):229-36.

6. Augustin S, Altamirano J, Gonzalez A et al. Effectiveness of pharmacologic and ligation therapy in high risk patients with acute esophageal bleeding. American Journal of Gastroenterology. 2011; 106(10):1787-95.

7. Villanueva $\mathrm{C}$, Piqueras $\mathrm{M}$, Aracil $\mathrm{C}$ et al. A randomized controlled trial comparing ligation and sclerotherapy as emergency endoscopic treatment added to somatostatin in acute variceal bleeding. Journal of Hepatology. 2006; 45(4):560-7.

8. Christensen E, Fauerholdt L, Schlichting P et al. Aspects of the natural history of gastrointestinal bleeding in cirrhosis and the effect of prednisone. Gastroenterology. 1981; 81(5):944-52.

9. Pugh RN, Murray-Lyon IM, Dawson JL et al. Transection of oesophagus for bleeding oesophageal varices. Br J Surg. 1973; 60(8):646-9.

10. Forrest JA, Finlayson ND, Shearman DJ. Endoscopy in gastrointestinal bleeding. Lancet. 1974; 2(7877):394-7.

11. Das DC, Mahtab MA, Rahim MA et al. Hepatitis B virus remains the leading causes of cirrhosis of liver in Bangladesh. Bangladesh Medical Journal. 2016; 45(3):164-6.

12. Olmo JA, Pena A, Serra MA et al. Predictor of morbidity and mortality after the first episode of upper gastrointestinal bleeding liver cirrhosis. Journal of Hepatology. 2000; 32(1):19-24.
13. Ghosh CK, Khan MR, Alam F et al. Peptic ulcer disease in Bangladesh: A multi-centre study. Mymensing Med J. 2017; 26(1):141-4.

14. Kirk AP, Dooley JS \& Hunt RH. Peptic ulceration in patients with chronic liver dsease. Dig Dis Sci. 1980; 25(10):756-60.

15. Siringo $S$, Burroughs $A K$, Bolondi $L$ et al. Peptic ulcer and its course in cirrhosis: An endoscopic and clinical prospective study. Journal of Hepatology. 1995; 22(6):633-41.

16. Kim DJ, Kim HY, Park CK et al. Helicobacter pylori infection and peptic ulcer disease in patients with liver cirrhosis. Korean J Intern Med. 2008; 23(1):16-21.

17. Bang CS, Baik GH, Kim JH et al. Peptic ulcer disease in liver cirrhosis and chronic hepatitis: Impact of portal hypertension. Gastrenterol. 2014; 49(9):1051-7.

18. Luo JC, Leu HB, Hou MC et al. Cirrhotic patients increased risk of peptic ulcer bleeding: A nationwide population based cohort study. Alimentary pharmacology and therapeutics. 2012; 36(6):542-50.

19. Holland-Bill L, Christiansen CF, Gammelager $\mathrm{H}$ et al. Chronic liver disease and 90 day mortality in 21359 patients following peptic ulcer bleeding-a nationwide cohort study. Aliment Pharmacol Ther. 2015; 41(6):564-72.

20. Tripodi A \& Mannucci PM. The coagulopathy of chronic liver disease. The New England Journal of Medicine. 2011; 365(2):147-56.

21. Wu CS, Lin CY, Liaw YF et al. Helicobactor pylori in cirrhotic patients with peptic ulcer disease: A prospective, case controlled study. Gastrointest Endosc. 1995; 42(5):424-7.

22. Saad RJ and Chey WD. Peptic ulcer disease in patients with chronic liver disease: Looking beyond bugs and drugs. Gastrointestinal endoscopy. 2005; 62(3):357-9.

23. Al-Akeely MH, Alam MK, Al-Salamah SM et al. Initial factors pre directing rebleeding and death in bleeding peptic ulcer disease. Saudi Med J. 2004: 25(5):642-7. 